Please do not remove this page

RMIT

UNIVERSITY

\title{
A unified hypothesis of coeliac disease with implications for management of patients
}

Cornell, Hugh; Stelmasiak, Teodor

https://researchrepository.rmit.edu.au/esploro/outputs/9921860368501341/filesAndLinks?institution=61RMIT_INST\&index=null

Cornell, H., \& Stelmasiak, T. (2007). A unified hypothesis of coeliac disease with implications for management of patients. Amino Acids, 33, 43-49. https://doi.org/10.1007/s00726-006-0420-0

Published Version: https://doi.org/10.1007/s00726-006-0420-0

Repository homepage: https://researchrepository.rmit.edu.au

(C) 2007 Springer

Downloaded On 2023/04/26 17:25:39 +1000

Please do not remove this page 

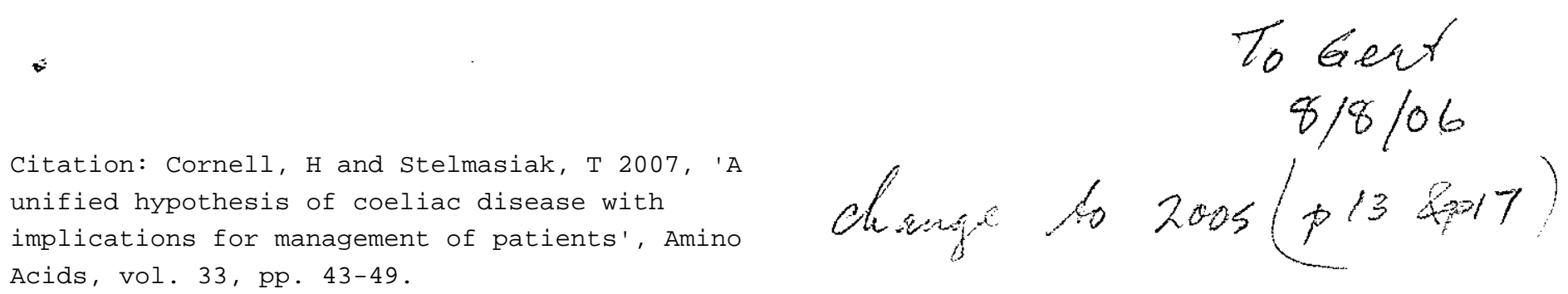

\section{Mini-Review :}

\section{A unified hypothesis of coeliac disease with implications for management of patients}

Hugh J. Cornell, RMIT University, School of Applied Sciences, Melbourne, Victoria, Australia and Teodor Stelmasiak, Glutagen Pty Ltd, Maribyrnong, Victoria, Australia.

Condensed title: A unified hypothesis of coeliac disease

\section{Summary}

This mini-review presents the research carried out within the context of two of the main hypotheses of the aetiology of coeliac disease. The enzymopathic hypothesis of the disease has been placed clearly as the underlying deficiency causing increased levels of toxic peptides, while the immunological hypothesis has been implicated in the pathogenesis of the disorder as the result of the action of undigested peptides in the small intestine. As a consequence, we are proposing a unified hypothesis of coeliac disease, which takes into account the actions of these undigested peptides through their direct cytotoxicity and their immunoactivity. At the same time, work aimed at defining some of these biologically active peptides, which could be said to be involved in the aetiopathogenesis of coeliac disease, will be reported.

The review also focusses on the use of enzyme therapy for management of the disease, which when used in conjunction with the gluten-free diet, offers a safeguard against damage to the small intestine caused by small amounts of gluten.

Key words: coeliac disease, enzyme therapy, gliadins, gluten, disease mechanisms, peptidases. 


\section{Introduction}

Coeliac disease (CD) has been described as an intolerance to certain proteins of wheat, barley and rye which lead to damage of the finger-like projections of the small intestine. Symptoms range from minor gastrointestinal complaints to severe malabsorption of nutrients caused by reduction in the absorptive surface of the duodenum and jejunum (Duggan,1997). At the cornerstone of treatment is dietary avoidance of these cereals, but there are difficulties because of the lack of clear advice on the food being gluten-free, particularly in situations where the food is prepared by people without a detailed knowledge of the ingredients and where the sufferers are young in years. If left untreated, serious consequences of malabsorption such as osteoporosis and anaemia, as well as lymphomas can occur (Duggan,1997). Early work by Frazer et al. (1959) suggested that the cause of the disease was an enzyme deficiency which allowed the accumulation of toxic peptide residues in the small intestine. They showed that peptic-tryptic digests of gluten still retained the toxicity demonstrated previously in whole gluten by Anderson et al.(1952). The use of peptic-tryptic-pancreatinic (PTP) digests of wheat gliadin (as would be physiological) was reported by Bronstein et al.(1966) and showed that toxicity was retained, enabling the study of low molecular weight oligopeptide mixtures (average molecular weight 1500 daltons) essentially free of polypeptides. This digestion technique was taken up by Cornell and Townley (1973a) who showed that one ion exchange fraction of this digest (Fraction 9) was digested to a lesser extent by duodenal mucosa from coeliac patients in remission than the other fractions of the digest. Mucosal digestion by the normal controls showed no such difficulties in digestion. Furthermore, Fraction 9 was 
shown to be much more toxic than the other fractions in in vitro cultures of biopsy tissue from patients with active disease (Townley et al.,1973) and by in vivo studies based on urinary xylose excretion (Cornell and Townley,1974). Serum antibodies were also directed at Fraction 9 and were higher than those in controls (Cornell,1974). An important milestone in this research was reached with the publication of the amino acid sequence of wheat A-gliadin by Kasarda et al.(1984), because this led to De Ritis et al.(1988) showing that certain amino acid sequences, called motifs, were associated with toxicity. They showed that PSQQ and QQQP were two such motifs present in peptides shown to be toxic in vitro. Since then, most of the in vitro and in vivo studies have confirmed the importance of one or both of these motifs (Wieser,1996).

Over the years, it seems that the symptoms associated with coeliac disease have changed from the classical rather severe gastrointestinal types to more covert ones such as fatigue, lethargy, depression and mild gastrointestinal ones such as stomach pain, bloating and the like. These symptoms are often associated with other illnesses and have contributed to the present problems of diagnosis, with the result that many patients are only diagnosed late in life, after malabsorption sequelae have become apparent.

It is still accepted that certain proteins of wheat, barley and rye are known to be the causative agents in CD and that some coeliacs are intolerant of oats (Cornell,1996). More is now known about the toxicity of $\alpha-, \beta$ - and $\gamma$-gliadins of wheat and the corresponding prolamins called hordeins (barley), secalins (rye) and avenins (oats), particularly in regard to peptides with certain sequences of amino acids which may be implemented in this toxicity. Glutenin proteins have not been studied as extensively as have the gliadins but 
they account for some of the toxicity of gluten.

It is also accepted that the disease is underdiagnosed even in countries like USA and Australia, and that the likely incidence of the disease is more likely to be about 1 in 250 , based on figures from Europe, where there is more emphasis on screening school children using immunologic tests which measure antibody levels to tissue transglutaminase (tTG). Up until now, the only form of treatment has been exclusion of gluten from the diet. However, a large majority of patients find it difficult to completely exclude gluten.

\section{The hypotheses of the cause of coeliac disease}

Several hypotheses have been proposed to account for the susceptibility of certain individuals to $\mathrm{CD}$ and these have been reviewed from time to time (Auricchio et al., 1985; Cornell, 1996). Two main hypotheses have remained the subject of research viz., The Enzymopathic Hypothesis and the Immunologic Hypothesis. The first has been attributed to Frazer et al.(1959), and the second to Falchuk and Strober (1974). A third hypothesis relating to a defect in the permeability of the intestinal mucosa in CD (Bjarnason and Peters, 1983) has also gained some support from recent work, which is discussed under Section 4.

Cornell and Stelmasiak now propose that these hypotheses can be unified, whereby the aetiology of the disease, embracing a peptidase deficiency, can be combined with the immunology of the disease, which is known to be responsible for much of the pathogenesis of the disease. Added to this assertion is direct cytotoxicity, which also damages tissue. The new hypothesis could thus be called a Unified Theory of the Mechanism of Coeliac Disease. 


\section{Progress through synthetic peptides}

Significant progress in the understanding of mucosal digestion of gliadin peptides in $C D$ has been made possible by the use of synthetic peptides based on the known A-gliadin structure (Kocna et al.1991). Using in vitro techniques based on digestion of these peptides by mucosal homogenates from patients with $\mathrm{CD}$ in remission, comparisons with digestion by mucosa from normal individuals showed that higher amounts of toxic peptide residues remain from coeliac mucosal digestion (Cornell and Rivett,1995; Cornell 1998). The foetal chick assay of Mothes et al.(1985) which was the main assay used, correlates well with those of human tissue in culture. Thus, defective digestion is at the core of the new theory, but needs to be coupled with pathogenetic mechanisms and cytotoxicity in order to explain the processes causing tissue damage. Kocna et al.(1991) used synthetic peptides based on the A-gliadin structure to verify this work, evaluating toxicity by means of the foetal chick assay (Mothes et al.,1985). An insight into the toxicity of Fraction 9 came from HPLC studies, which showed that the toxicity was due to both a tyrosine containing peptide corresponding to residues 75-86 of A-gliadin and to a serine containing peptide corresponding to residues 6-19 (Cornell et al.,1992). Working with the 6-19 peptide, using an amino acid deletion technique, it was shown that the octapeptide 12-19, of structure NPSQQQPQ, containing the motifs PSQQ and QQQP in overlapping sequences, was toxic, reinforcing the view that residual octapeptide sequences of this type are large enough to retain toxicity, whereas the hexapeptide 13-18 is not (Cornell and Mothes, 1993;1995).

These in vitro techniques based on digestion of synthetic peptides by remission coeliac 
mucosa were valuable in that they not only pointed to a deficiency in digestion by the remission coeliac mucosa but they also indicated the types of residual peptides, such as peptide 12-19 above. The studies also showed that residues of peptides remaining after digestion of the toxic peptides from the tyrosine-containing peptide could be toxic. For example,the coeliac mucosal digestion of peptide 75-86, RPQQPYPQPQPQ, resulted in major amounts of residues of the active octapeptide 77-84 (QQPYPQPQ), compared against normal mucosal digestion. These separate studies both showed that the amounts of undigested residues from the two types of peptides were much higher with the remission coeliac patients than with the normal controls under the same conditions.

The serine-containing peptides ( especially peptide 11-19) displayed very potent cytotoxicity in the foetal chick assay (Cornell and Mothes, 1995) whereas, the tyrosine containing peptides were much more immunogenic (Cornell et.al.1994). The significance of the PSQQ motif in cytotoxicity has been reinforced by the in vivo toxicity of peptide 206-217, LGQGSFRPSQQN, where the only recognised toxicity motif is PSQQ (Mantzaris and Jewell,1991).

The peptide 31-49 has also been shown to be toxic in vivo, which is significant in that it contains both the QQQP and QQPY motifs in its sequence LGQQQPFPPQQPYPQPQPF. The QQPY motif is likely to be the one conferring immunogenicity.

Other immunoreactive peptides have been reported, such as peptide 57-73 of A-gliadin with residues 69 and 73 transposed (Anderson et al.,2000), and the 33-mer peptide corresponding to residues 57-89 from $\alpha-2$ gliadin (Shan et al.,2002). However, both these peptides lack the PSQQ and QQQP motifs associated with toxicity and their activity may 
depend on the fact that they are both tyrosine-containing peptides. Only the latter peptide has the QPYP motif common to all three coeliac-toxic cereals ( Mc Lachlan et al., 2002). Auricchio points out the need to differentiate between the toxic and the immunoactive peptides, as they are not necessarily the same. He cites, for example, the A-gliadin peptide 56-68, a dominant epitope for coeliac intestinal CD4+ T cells (McAdam and Sollid, 2000) which is not able to cause damage in vitro to the intestine of coeliac patients ( De Ritis et al. 1988). Therefore, it has been suggested that non-immunomediated cytotoxity of gliadin peptides on the small intestine might also be involved in the pathogenesis of $\mathrm{CD}$, which is supported by gliadin peptides having toxic action on foetal rat jejunum but not on mature jejunum (Auricchio et al.,1984).

Secondary structural differences in the toxic serine-containing peptides, which favour an $\alpha$ - helical structure and the tyrosine-containing peptides, which have a high $\beta$-turn content, are consistent with the different types of toxicity displayed (Cornell and WillsJohnson, 2000). A 20-mer peptide from the N-terminal region of an avenin, with strong reactivity to anti-gliadin antibodies in coeliac sera was also shown to have a high $\beta$-turn content by circular dichroism (Alfonso et al,1998). Thus, a role for $\beta$ - turn motifs in the recognition of these antibodies was suggested and the presence of the QQQP motif pointed to its potential toxicity. The data presented so far provide evidence for defective mucosal digestion in remission coeliac small intestinal mucosa and point to the lack of a peptidase in coeliac mucosa which is required to digest certain sequences of amino acids, including the 4-mer motifs PSQQ, QQQP and QQPY, as component parts of mainly octapeptides (Cornell,1998). 
This particular peptidase is present in normal small intestinal mucosa, but is obviously deficient in remission coeliac mucosa, and appears to be necessary for disrupting these motifs. There is the possibility of a deficiency of more than one type of peptidase. Coupled with proteomics, studies of the motifs associated with toxicity will help to define toxic peptides in cereals other than wheat.Already, it has been shown that extended motifs such as QQPYP, PQQPY and QQQPFP are common to wheat, barley and rye (Mc Lachlan et al., 2002) and are all present in the toxic peptide $31-49$ of wheat A-gliadin (Sturgess et al.,1994).

\section{Immunological aspects of tissue damage}

The evidence for damage to tissue as the result of immunological mechanisms is overwhelming but the evidence that it represents an aberrant reaction as a result of an abnormal presentation of gliadin is much less convincing (Biagi et al.,1999). We therefore opt for the concept that these mechanisms only operate as the result of a build-up of partially digested peptides which are capable of inducing an immune response which could depend upon prior cytotoxic action. The common modern view of the immunological mechanism is that HLA class II molecules in antigen - presenting cells expose processed peptides to immunocompetent T-cells which initiate the pathogenesis of the disease (Maki 1997). On presentation of these epitopes, the T-lymphocytes respond by releasing cytokines which elicit changes in small intestinal cells through an inflammatory response. These processes damage enterocytes and other cells in the gut. The T-cell mediated response in susceptible individuals occurs because of recognition of specific peptides by certain T-cells when presented to DQ2 and DQ8 molecules on the 
surface of these cells. Potentiation of binding, and hence activity, by tissue transglutaminase reacting with specific glutamine residues in the gliadin fragments can bring about autoimmune mechanisms ( Schuppan and Hahn,2002). Vader et al.(2002), showed that gluten-specific T-cell responses in HLA-DQ2 positive adult coeliac patients are directed at multiple peptides derived from gliadin and glutenin. The responses of some of these peptides were not always enhanced by tTG. The authors made the point that when tissue damage progresses, the release of cytoplasmic tTG could enhance the gluten-specific response to the strongest binding peptides.

There has been an interest recently in mechanisms which could account for increased epithelial permeability of the small intestine and resulting elevated levels of antigen presentation (Monsuur et al., 2005). The authors attributed this increased permeability to an impairment of the intestinal barrier through a myosin variant, $\mathrm{IXB}$, and suggested it could be a primary defect. Another mechanism of increased permeability has been suggested by Drago et al. (2006) who found that when intestinal biopsies from coeliac patients in remission were exposed to luminal gliadin, a sustained release of zonulin was observed, together with an increase in intestinal permeability, which was blocked by a zonulin antagonist. Controls from individuals without $\mathrm{CD}$ showed a limited zonulin release but the increase in intestinal permeability was much smaller. This diminished effect could be due to more efficient digestion of the gliadin by the normals but the answers to these questions regarding permeability mus await the outcome of further experiments aimed at defining whether these data represent primary defects or susceptibility factors. In this respect, experiments showing the effects of a gluten-free diet would be enlightening. 
With further regard to pathogenesis, the CD4+ gluten-sensitive T-lymphocytes mentioned previously, may represent only part of the mechanism of pathogenesis because peptide 3149 of A-gliadin is toxic in vivo ( Sturgess et al.,1994) yet it produces no small intestinal Tcell response. Even so, a monoclonal antibody to this peptide has been produced ( Ellis et al.,1998).

Although most patients with coeliac disease carry the risk alleles encoding the HLADQ2, it should not be assumed that this is the only condition for manifestation of CD. Certainly, the genetic association of the disease is evident from these types of studies, but it must be remembered that the prevalence of HLA-DQ2 is high (about $25 \%$ ) in the Northern European population, suggesting that additional genes are probably involved in CD (Duggan,1997). As the incidence of CD is less that $1 \%$ in such a population, more specific factors, probably non-HLA related genes, are possibly involved (Maki,1997). We would maintain that these reactions occur because, in coeliacs, the concentration of undigested peptides is higher due to defective digestion of specific gliadin fragments. These fragments are the triggers initiating direct cytotoxicity and all the aforementioned reactions. Thus, whether we have high concentrations of the cytoxic serine-containing peptides or the immunoactive tyrosine-containing peptides, complete digestion of both these types of peptides would prevent the pathogenesis of the disease. No such damaging reactions occur in normal individuals because digestion of the gluten peptides is much more complete. The aetiology of $\mathrm{CD}$ shares many similarities with dermatitis herpetiformis, where the skin is also affected. However, both are quite different from wheat allergy. 


\section{Successful intervention -Enzyme Therapy}

Early studies showed that pre-treatment of gluten with crude papain reduced the toxicity of the untreated gluten to coeliac patients, as assessed by faecal fat determinations (Messer et al.,1964). This reduction was not evident when pure papain was used. Subsequently, detoxification was attributed to an enzyme called glutamine cyclotransferase. The enzyme attacks $\mathrm{N}$-terminal glutamine residues in gluten digests forming $\mathrm{N}$-pyrrolidone carboxylyl peptides, which appear to be much less toxic.

The first example of the application of enzyme therapy was by Messer and Baume (1976). Their approach was to attenuate the symptoms of $\mathrm{CD}$ in a patient by using the crude papain in an enterically coated tablet in order to allow it to work in the small intestine. Clinical trials needed to have been carried out to substantiate these findings and gain confidence with this type of enzyme, but nevertheless, it opened the way for enzyme therapy for palliative care of coeliac patients.

In more recent studies, the basic premise behind the alleviation of symptoms by the use of enzyme therapy is that the pathogenesis cannot occur if the gluten proteins are digested to amino-acids and very small peptides. It is well known that the collective amino acids which comprise gluten are not toxic to individuals with $\mathrm{CD}$. After the large series of experiments which provided evidence for an enzyme deficiency in $\mathrm{CD}$, the ability of porcine or bovine intestinal extracts to complete the digestion in vitro of peptic-trypticpancreatinic digests of gliadin (from wheat gluten) was observed (Cornell and Stelmasiak,2004).

A clinical trial to test the efficacy of these extracts in countering the effects of a modest 
gluten challenge in patients with CD was conducted at the Royal Melbourne Hospital . Volunteers were 21 biopsy-proven adult volunteers who were on a gluten-free diet. The trial was of double-blind crossover design using a placebo and the enzyme extract in enterically-coated capsules. The results showed there were benefits in this type of enzyme therapy as symptoms were ameliorated in the vast majority of those patients who developed moderate-severe symptoms (Cornell et al.,2005). In the 6 patients who were biopsied, histological examination showed that 5 showed abnormalities at the start of the trial, but that further damage as the result of the gluten-challenge was reduced by means of the intervention with enzyme extract. Antibodies to tTG and gliadin (Dahele et al., 2001) were roughly correlated with the severity of histological damage, but there was no significant correlation in antibody titres with symptoms produced by the challenge across all patients, nor was there any significant reduction in antibody titres with enzyme therapy (Cornell et al,2005). However, it seems that a promising new approach to patient management is emerging, representing a new breakthrough after 50 years of sole treatment by a gluten-free diet. The enzyme extract will enable patients to gain the benefit of complete exclusion of gluten by functioning as a safeguard.

\section{Why enzyme therapy is successful}

The active enzymes in these animal intestinal extracts are able to digest the toxic peptides in a PTP digest of gliadin and reduce their deleterious effects. Their effectiveness can be measured by their ability to protect rat-liver lysosomes from the action of PTP digests (Comell and Townley,1973 b). The substrates involved include the serine - and tyrosinecontaining peptides in the region of residues $6 m 19$ and 75-86 respectively of A-gliadin, 
but other active fragments such as $31-49$ would be included. When we look at peptide, $75-$ 86 (RPQQPYPQPQPQ), we notice it contains the QQPY motif of the toxic residual octapeptide 77-84 and the toxic peptide 31-49. Normal mucosal digestion of peptide 7586 reduces the amounts of residual peptides considerably and hence would lessen the consequential immunological reactions (Cornell,1998).

With regard to the serine-containing peptides, one of the most toxic is peptide 11-19 of Agliadin (QNPSQQQPQ). An enzyme which attacks the PSQQ motif appears to be missing in remission coeliac mucosa (Cornell and Rivett,1995), but it is unknown whether it is the same enzyme that is required for digestion of the tyrosine peptides. The ability of both normal intestinal mucosa and animal intestinal extracts to detoxify Fraction 9 (Cornell and Stelmasiak,2004) and peptic-tryptic digests of gluten indicates that such enzymes must be present in the animal intestinal extracts, a point not lost on Frazer et al. (1959).

\section{What type of enzyme is missing?}

Several early investigations reported the presence of specific peptidases, capable of splitting small peptides, in the cytoplasm and brush border of animal enterocytes ( Slaby et al.,1978).They found endopeptidase activity in the supernatant of the mucous membrane of human small intestine homogenised with Triton X-100. Splitting of oligopeptides can occur by stepwise deletion of amino acids, but there is now evidence to suggest that the motifs associated with toxicity are a barrier to attack (Cornell,2006). Assays of brush border and cytosol peptidase activities in the small intestine of coeliac patients revealed that Aminopeptidase A was the only significantly reduced peptidase 
activity in children with $\mathrm{CD}$ in remission, compared with control children ( Generoso et al.,1980).The substrate used here was $\alpha$ - glutamyl- $\beta$ - naphthylamide and the average values of enzyme activity were reduced to $70 \%$ of controls in 8 patients $(p=0.01)$. These experiments should perhaps be extended to include substrates that contain the 4-mer motifs associated with toxicity, otherwise there is only a small chance of finding the enzyme responsible for detoxification of the oligopeptides.

The structure of peptide 75-86, with its five proline residues suggests the possibility of a prolyl endopeptidase as the missing enzyme in $\mathrm{CD}$ and the one present in the animal mucosal extracts. However, reports to date indicate only a limited role for this enzyme in the detoxification of gluten (Matysiak-Budnik et al.,2005). Furthermore, no deficiency of this enzyme in remission coeliac mucosa has been detected (Donlon and Stevens,2004). There is still the likelihood of the enzyme being an endopeptidase required to attack motifs associated with toxicity, but it is most unlikely to be prolyl endopeptidase because this enzyme would be depleted in mucosa from remission coeliacs in remission.

\section{Conclusions}

There needs to be a more concentrated effort in diagnosis of $\mathrm{CD}$, as the symptoms, particularly in adults, can be quite covert. This means that it is imperative to diagnose the disease in early childhood, as this also avoids the adverse psychological symptoms, which are apparent in some teenage children with untreated $\mathrm{CD}$ as well as the long term effects of malnutrition. The use of blood tests for determining levels of antibodies to tissue transglutaminase is highly recommended, followed by biopsy of the small bowel. The use of enzyme therapy based on animal intestinal extracts is strongly suggested as a 
safeguard, since despite better food labelling, it is still extremely difficult to maintain a strict gluten-free diet. A clinical trial has indicated that an encapsulated form of porcine intestinal extract is helpful in counteracting symptoms caused by modest amounts of gluten and should enable the small bowel to recover from traces of gluten accidentally ingested by patients trying to follow a gluten-free diet.

A unified theory of $\mathrm{CD}$ now emerges where the aetiology of the disease is recognised as defective digestion of gluten, followed by immunological reactions and direct cytotoxicity resulting from the abnormally high concentrations of certain undigested peptides. Thus, for the disease to manifest itself, both the aetiology and pathogenesis are mutually linked and thus the term aetio-pathogenesis could be used to encapsulate the complex events leading to damage of the small intestine. The key defect in coeliac disease is probably a genetic one which prevents biosynthesis of certain peptidases and that individuals of DQ2 and DQ8 haplotyping are the most susceptible.

\section{Acknowledgement}

The authors are greatly indebted to Professor Finlay Macrae, Head of the Department of Colorectal Medicine and Genetics, Royal Melbourne Hospital Campus of the University of Melbourne, without whose supervision the clinical trial of enzyme therapy could not have been accomplished.

\section{References}

Alfonso P, Soto C, Albar JP, Camafeita E, Escobar H, Suarez L, Rico M, Bruix M, Mendez E (1998) $\beta$-Structure motif recognition by anti-gliadin antibodies in coeliac disease. FEBS Letters 427: 36-40 
Anderson CM, Frazer AC, French JM, Gerrard JW, Sammons HG, Smellie JM (1952) Coeliac disease: gastroinstestinal studies and the effect of dietary wheat flour. Lancet i:836-842

Falchuk ZM, Strober W(1974) Gluten-sensitive enteropathy: synthesis of anti-gliadin antibody in vitro. Gut 15: 947-952

Anderson RP, Degano P, Godkin AJ, Jewell DP, Hill AVS (2000) In vivo antigen challenge in celiac disease identifies a single transglutaminase-modified peptide as the dominant A-gliadin T-cell epitope. Nat Med 6: 337-342

Auricchio S, Cardelli M, DeRitis G, De Vincenzi M, Lattes F, Silano V (1984) An in vitro animal model for the study of cereal components toxic in coeliac disease. Pediatr Res 18:1372-1378

Auricchio S, De Ritis G, De Vincenzi M, Silano V (1985) Toxicity mechanisms of wheat and other cereals in celiac disease and related enteropathies. J Pediatr Gastroenterol Nutr 4:923-930

Biagi F, Zimmer KP, Thomas PD, Ellis HJ, Ciclitira PJ (1999) Is gliadin misrepresented to the immune system in coeliac disease? A hypothesis. Quart J Med 92:119-122 Bjarnason I, Peters TJ, (1983) A persistent defect in small intestinal permeability in coeliac disease demonstrated by a 51-Cr-labelled EDTA absorption test. Lancet i: 323-325 Bronstein HD, Haeffner LJ, Kowlessar OD (1996) Enzymatic digestion of gliadin; the effect of the resultant peptides in adult coeliac disease. Clin Chim Acta 14: 141-155 Cornell HJ (1974) Circulating antibodies in wheat gliadin fractions in coeliac disease. Arch Dis Childh 49:454-458 
Cornell HJ (1996) Coeliac Disease: A review of the causative agents and their mechanism of action. Amino Acids 10: 1-19

Cornell HJ. (1998) Partial in vitro digestion of active gliadin-related peptides in coeliac disease. J Protein Chem17: 739-744

Cornell HJ. (2006) The aetiology of coeliac disease and its significance for therapy.

Current Topics in Peptide and Protein Research 7: 17-22

Cornell HJ, Macrae FA, Melny J, Pizzey C, Cook F, Mason S, Bhathal P, Stelmasiak T (2005) Enzyme therapy for management of coeliac disease. Scand J of Gastroenterol 40:1304-1312

Cornell HJ, Mothes T (1993) The activity of wheat gliadin peptides in in vitro assays for coeliac disease. Biochim Biophys Acta 1181:169-173

Cornell HJ, Mothes T (1995) Further studies of the in vitro activity of synthetic gliadin peptides in coeliac disease. Biochem Biophys Acta 1270:168-172

Cornell HJ, Rivett DE(1995) In vitro mucosal digestion of synthetic gliadin-derived peptides in coeliac disease. J Protein Chem 14:335-339

Cornell HJ, Skerritt JH, Puy R, Javadpour M (1994) Studies of in vitro $y$ interferon production in coeliac disease as a response to gliadin peptides. Biochim Biophys Acta1226:126-130

Cornell HJ, Stelmasiak T (2004) Enzyme supplementation in coeliac disease. 11th International Symposium in Coeliac Disease. Belfast. P196 Cornell HJ, Townley RRW (1973a) Investigating possible intestinal peptidase deficiency in coeliac disease. Clin.Chin.Acta 43: 113-125 
Cornell HJ, Townley RRW (1973b) The effect of gliadin peptides on rat liver lysosomes in relation to the pathogenesis of coeliac disease. Clin Chim Acta 49:181-188

Cornell HJ, Townley RRW (1974) The toxicity of certain cereal proteins in coeliac disease. Gut 15:862-869

Cornell HJ, Wieser H, Belitz, H-D (1992) Characterization of the gliadin-derived peptides which are biologically active in coeliac disease. Clin Chim Acta 213:37-50 Cornell HJ and Wills-Johnson G (2000) Structure-activity relationships in coeliac-toxic peptides. Amino Acids 21:243-253

Dahele AVM, Aldhaus MC, Humphreys K, Ghoskh S (2001) Serum IgA tissue transglutaminase antibodies in coeliac disease and other gastrointestinal diseases.

Q J Med 94: 195-205

De Ritis G, Auricchio S, Jones HW, Lew EJ-L, Bernardin JE, Kasarda DD (1998) In vitro (organ culture) studies of the toxicity of specific A-gliadin peptides in coeliac disease. Gastroenterology 94:41-49

Donlon J, Stevens FM (2004) No lack of prolyl oligopeptidase (POP) in the coeliac mucosa: $11^{\text {th }}$ International Symposium in Coeliac Disease. Belfast. P198

Drago S, El Asmar R, Di Pierro M, Clemente MG, Sapone ATA, Thakar M, Iacono G, Carroccio A, D'Agate C, Not T, Zampini L, Catassi C, Fasano A.(2006) Gliadin,zonulin and gut permeability: effects on celiac and non-celiac intestinal mucosa and intestinal cell lines. Scand J of Gastroenterol 41: 408-419

Duggan JM. (1997) Recent developments in our understanding of adult coeliac disease. MJA 166:312-315 
Ellis HJ, Rosen-Bronson S, O'Reilly N, Ciclitira PJ (1998) Measurement of gluten using a monoclonal antibody to a coeliac-toxic peptide of A-gliadin. Gut 43: 190-195 Falchuk ZM, Strober W (1974) Gluten-sensitive enteropathy: synthesis of anti-gliadin antibody in vitro. Gut 15:947-952

Frazer AC, Fletcher RF, Ross CAC, Shaw B, Sammons HC, Schneider R(1959) Gluten induced enteropathy; the effect of partially digested gluten. Lancet ii:252-255

Generoso A, Cucchiara S, de Vizia B, de Ritis G, Mazzacca G. Auricchio S (1980) Brush border and cytosol peptidase activities of human small intestine in normal subjects and coeliac patients. Pediatr Res 14:812-818 Kasarda DD, Okita TW, Bernardin JE, Baecker PA, Nimmo CC, Lew EJ, Dietler MD, Greene FC (1984) Nucleic and (cDNA) and amino acid sequences of $\alpha$-type gliadins from wheat (Triticum aestivum). Proc Natl Acad Sci USA 81: 4712-4716

Kocna P, Mothes T, Krchnak V, Fric P (1991) Relationship between gliadin peptide structure and their effects on the foetal chick duodenum. Z LebensmUnters Forsch $92: 116-119$

McAdam SN, Sollid LM (2000) Getting to grips with gluten. Gut 47:743-745

McLachlan A, Cullis PG, Cornell HJ (2002) The use of extended motifs for focussing on toxic peptides in coeliac disease. J Biochem Mol Biol. and Biophys 6:319-324

Maki M. (1997) Coeliac disease. Lancet 3491755-1759

Mantzaris G, Jewell DP (1991) In vivo toxicity of a synthetic dodecapeptide from Agliadin in patients with coeliac disease. Scand J Gastroenterol 26:392-398 Matysiak-Budnik T, Candalh C, Cellier C, Dugave C, Namane A, Vidal-Martinez T, 
Cerf-Bensussan N, Heyman M (2005) Limited efficiency of prolyl-endopeptidase in the detoxification of gliadin peptides in coeliac disease. Gastroenterology 129:786-796 Messer M,Anderson CM, Hubbard L (1964) Studies on the mechanism of destruction of the toxic action of wheat gluten in coeliac disease by crude papain. Gut 5: 295-303 Messer M, Baume (1976) Oral papain in gluten intolerance. Lancet ii: 1022 Mothes T, Muhle W, Muller F, Hekkens W Th JM (1985) Influence of gliadin on fetal chick intestine in tissue culture. Biol Neonate 48: 59-64

Monsuur AJ, de Bakker PIW, Alizadeh BZ, Zhernakova A, Bevova MR, Strengman E, Franke L, van't Slot R, van Belsen MJ, Lavrijsen ICM, Diosdado B et al. (2005) Myosin IXB variant increases the risk of celiac disease and points toward a primary intestinal barrier defect. Nature Genetics 37: 1341-1344

Schuppan D, Hahn EG (2002) Gluten and the gut - lessons for immune regulation. Science 297:2218-2220

Shan L, Molberg O, Parrot I, Hausch F, Feliz F, Gray GM, Sollid LM, Khosla C (2002) Structural basis for gluten intolerance in celiac sprue. Science 297: 2275-2279 .Sturgess R, Day P, Ellis HJ, Lundin KEA, Gjertsen HA, Kontakov M, Ciclitira PJ (1994) Wheat peptide challenge in coeliac disease. Lancet 343:758-761

Slaby J, Fric P, Kasafirek E (1978) Endopeptidase activity in the brush border of human enterocyte. Acta Heptato-Gastroenterol 25:295-302

Townley RRW, Comell HJ, Bhathal PS, Mitchell JD (1973) Toxicity of wheat gliadin fractions in coeliac disease. Lancet i: 1363-1364

Vader W, Kooy Y, van Veelen P, DeRu A, Harris D, Benckhuijsen W, Pena S, Mearin L, 
Drufhout JW, Koning F (2002) The gliadin response in children with celiac disease is directed toward multiple gliadin and glutenin peptides.Gastroenterology 122: 1729-1737 Wieser H (1996) Relation between gliadin structure and coeliac toxicity. Acta Paediatr Suppl 412: 3-9

Author's address:

Prof. Hugh J. Cornell

School of Applied Sciences

RMIT University

GPO Box 2476V

Melbourne, Victoria 3001

Australia

e-mail < hugh.cornell@,rmit.edu.au > 